\title{
HISTORIA Y MEMORIA. ReVISITANDO A JUAN BENET
}

\author{
Adriana Minardi \\ (Universidad de Buenos Aires)
}

\section{USOS DEL PASADO: EL TESTIMONIO EN EL CRUCE ENTRE HISTORIA Y MEMORIA}

«La memoria es el alma y el alma debe ser poco más que la memoria pues no existe un sólo acto psíquico del que la memoria pueda estar ausente»

[Benet 1965: 37]

Podríamos decir que, a partir de 1975, comienza en España un proceso de repatriación de la historia que se impuso a través de tres olvidos: el de la república, el de la guerra civil y el del franquismo, pautado por la transición democrática. Si entendemos que «toda narración, autobiográfica o novelesca, histórica o inventada depende de la memoria de alguien» [Vernon 1989:429], uno de los primeros actos en un relato es construir y representar una memoria ficticia e imitar el proceso rememorativo atendiendo a una concepción determinada de la memoria. Esta concepción depende de una estructura específica que conjuga una poética y una narrativa. Si toda memoria histórica supone una política de la memoria' ${ }^{1}$, su corporización se ve reflejada en un proyecto que, desde los años ochenta, busca recuperar un pasado republicano anulado. En un nivel descriptivo, las temáticas de estos relatos, ensayísticos en su mayoría, de la memoria no se oponen a la historiografía emergente de esta época, como hemos ya analizado², pues su misma configuración apunta a una crítica de la memoria oficial y de componente más nacionalista de la guerra civil y el totalitarismo franquista. Éstas buscan, por consiguiente, la integración del saber, sentir, actuar, colectivos [Winter 2006]. Las creencias colectivas delinean una política de

1 Como lo ilustra la polémica entre Eric Hackl [2001a, 2001b] y Antonio Muñoz Molina [2001] acerca del «hacer memoria» en torno de Sefarad y a propósito del testimonio y la historia.

2 Ver: Minardi, A. «El sentido de práctica discursiva en Qué fue la guerra civil, de Juan Benet. La construcción del intelectual después de Franco», Espéculo, revista digital cuatrimestral de la UCM (Universidad Complutense de Madrid), Madrid, España, $\mathrm{n}^{\circ} 32$, marzo de 2006. 
la memoria que deja de leer en la historia los relatos de los grandes hombres para buscar restos de la República en la microhistoria cotidiana y en el análisis de los procesos de larga duración. La inclusión del mundo histórico, así fuere bajo la forma de la ironía o de la crítica explícita, proyecta la idea de una rememoración que busca la totalidad y que entiende que la hegemonía presenta una contrahegemonía ${ }^{3}$. La historia estaría sumida en procesos de cambio constante lo que sería, a su vez, el indicio de un quiebre entre la memoria transmitida (Erfahrung) y la vivida (Erlebnis), a partir del declive moderno de la religión cristiana, dando paso a la construcción del concepto de «religión civil» por el que se producirían nuevas interpretaciones políticas y sociales de la memoria4 . En este sentido, los trabajos de J. Assman [1992] centran el problema en cómo se transforma la historia. Este punto es central para comprender también el desplazamiento de la memoria viva a la memoria cultural. Por lo que dicho proceso, en la narrativa de Juan Benet, tanto en la ensayística como en sus novelas, se focaliza en la superación del mito de las dos Españas, que lejos de ser ya una aporía existencial se vuelve necesariamente un dilema epistemológico. Recordar, hacer historia, hacer la historia suponen axiomas prácticos que, lejos ya también del ámbito privado, asumen, incluso en tensión con la intimidad, la responsabilidad de la publicidad. Estas características, como señala E. Traverso [2000], suponen una dimensión política de la memoria colectiva, lo que afectaría las formas del hacer historia. Así, la búsqueda del pasado también ha hecho de la memoria, cuyo soporte privilegiado es el relato testimonial, el problema central de la novela histórica. La progresiva hibridación del género narrativo, y en especial de la novela, hace imposible la separación entre historia y memoria y obliga a pensar que la historia no pertenece ya a la esfera prototípicamente científica y pública, y la memoria a una individual o colectiva sino que la memoria cultural, al ser esa búsqueda del pasado, se nutre indefectiblemente de la historiografía así como también de la literatura testimonial. Lo mismo que para la historia (QFGC, LCGC) ${ }^{5}$ ocurre para la concepción de memoria, como puede verse en «Épica, Noética, Poiética» [1970: 9-46] respecto de la canción popular«La gallina ética», atribuida a Aristóteles.

\footnotetext{
3 Partimos de la perspectiva teórica, superadora de concepto de ideología por la que A. Gramsci entiende lo hegemónico a partir de su relación dialéctica con la contrahegemonía.

4 La sacralización de la memoria no sólo la opone a la Historia sino que tiende a asimilarla al acontecimiento, ya que el testimonio no reproduce una realidad fáctica fundadora sino que él mismo se constituye en tanto acontecimiento.

5 Las abreviaturas de los títulos de Juan Benet se encuentran recogidas al final del texto.
} 
Se diría que la imagen de la memoria traída a colación es de nuevo impresa cada vez que se recuerda, al tiempo que se destruye la imagen anterior como una copia inútil y carente de actualidad que no merece ser guardada en el reducido archivo de la mente. De forma que cada recuerdo es una nueva simplificación $-\mathrm{y}$, cuando menos, alteración- de las imágenes de la memoria que poco a poco va convirtiendo a la estampa del objeto original en una de tantas abstracciones con que el pensamiento se tiene que conformar para llevar a cabo con agilidad sus numerosas funciones: palabras, ideas, líneas, siluetas o colores. [31]

La memoria, como parte de la Cultura, entonces, agrupa tanto al testimonio como al discurso histórico. Ambos se sitúan en el marco de la fenomenología, marco del que K. Benson [1989] parte para caracterizar la narrativa benetiana. De esta forma, la referencia es una construcción subjetiva y la memoria juega un rol central por cuanto funciona como el pilar proyectual literario de Juan Benet, que apunta al desmontaje de la tradición realista española y a la construcción de un gran estilo perdido en la «Entrada en la taberna» [1965: 9]. Esto explica que la estructura narrativa responda a una simbología, tanto histórica como testimonial, a partir de la metáfora del estado de ruina. El modo de «la estampa $»^{6}$ propone esa estructura ligada a la rememoración que cifra todo el valor en la imagen [1965:151], mientras que el modo del argumento «se cifra en la composición en interacción de unas líneas de convergencia (...) que carecen de razón si no hay un principio y un fin» [lbid.].

Esta forma de la temporalidad interna no cronológica trae consigo una concepción altamente espacial de la narrativa que funcionaliza la ruina como el espacio de la memoria utópica. Para superarla es necesaria la recuperación de la tradición literaria, entendida como la narrativa o el texto escribible ${ }^{7}$ que hace posible la conjunción de la Historia y la memoria comunicativa como parte de una memoria cultural a partir de los grandes temas del hombre. Estas temáticas recuperan, en especial, la memoria republicana y los valores reformistas; particularmente, aqueIlos de la tradición krausista y se materializan narrativamente en lugares específicos que ya no

6 También definido como «una zona de sombra, no sólo donde el conocimiento no ha entrado todavía, sino ante el cual se detiene y suspende toda actividad. Eso es el misterio» [1976b: 50]. Ver también la referencia a este concepto que retoma J, Margenot III [1991] en Zonas y sombras: aproximaciones a Región de Juan Benet.

7 La narrativa, en tanto experimenta formas nuevas, tiene la función de crear un texto escribible, en la terminología de Barthes. Para Benet sólo el texto escribible es el que realmente es literario, mientras que el legible se correspondería con el propio del realismo tradicional. De esta forma, el gran estilo es propio de «una literatura que no sintiéndose apremiada por la obligación de representar la naturaleza también progresivamente va eliminando de su código la necesidad de ser inequívoca, veraz y certera» [1976: 48]. La narrativa, entonces, los presenta para «demostrar la insuficiencia gnoseológica y la insolubilidad de aquéllos; e incluso (...) de fomentar la invención de aquella clase de misterio que por su naturaleza se encuentra y se encontrará siempre más allá del poder del conocimiento» [íbídem: 48-49]. 
son solamente propios de la topografía sino también producto de una topología, dada por la memoria discursiva republicana. En este sentido, los lugares de memoria, según señala P. Nora [1997], abren el juego a ambas posibilidades: tanto a la deconstrucción ${ }^{8}$ de aquellas topografías en tanto topologías, como a la emergencia de aquéllas caídas frente a la hegemonía del nacionalismo católico y el proyecto innovador de la tecnocracia del Opus Dei en la última fase del franquismo. La memoria brinda una dimensión temporal así como una conciencia del pasado $y$, de esta manera, la obliga a enfrentarse con sus propias condiciones de existencia, que son colectivas, en el sentido en que lo define M. Halbwachs [1968]. Las memorias comunicativas de aquellos silencios que hemos mencionado deben reconstruirse en la narrativa para entrar en el campo de la memoria colectiva que es la que se compone tanto de la memoria oficial, histórica, como de la comunicativa.

Si a la división que presenta Halbwachs entre historia y memoria se le opone una síntesis con la noción de memoria cultural y colectiva, queda claro que es la narrativa la que viene a subsanar ese hiato $^{9}$ al intentar reestablecer la continuidad que la historia, en tanto sentido, tiene para la memoria. Si la historia presupone un saber científico acerca del pasado, la memoria comunicativa, según J. Assman, se crea de manera informal por el contacto directo entre las generaciones. La memoria cultural, que es colectiva, comprendería tanto la historia como la memoria comunicativa y se correspondería con el saber común al cual recurre una comunidad, sociedad o nación para crear su identidad [Assman, 1992]. Se encargaría también de organizar e institucionalizar las formas de recordar el pasado porque este saber es, ante todo, pragmático. De esta manera, la historia contribuye a la memoria cultural de la misma manera que la memoria comunicativa pero, en contraposición a la idea de una continuidad entre el testimonio o memoria comunicativa y la historia, que oficiaría como su elemento configurador para la posteridad, la narrativa benetiana entiende que esta última, determinada por la guerra civil, viene a romper con la memoria comunicativa y a instalar imperativamente la memoria oficial, histórica, representada por el franquismo. El orden lógico/causal o cronológico del relato realista es un orden

8 Muchos autores, como por ejemplo M. Valdéz [1989], proponen como concepto preferiblemente español el de desmontaje en oposición al derrideano.

9 «If a memory exists only when the remembering subject, individual or group, feels that it goes back to its remembrances in a continuous movement, how could history ever be a memory, since there is a break in continuity between the society reading this history and the group in the past who acted in or witnessed these events [Halbwachs, 1968: 79]. 
impuesto por el afán de sistematización de la razón. En la poética benetiana se propone, en cambio, la distorsión como modo de ruptura de este exceso determinista propio de la narrativa realista. Esta distorsión, propia de la construcción de una zona de sombras, propone la libertad de una rememoración no ligada al principio mimético sino al claroscuro propio de la estructuración de la memoria que será central en las novelas benetianas. La antítesis básica de un acontecimiento como la guerra civil surge por la oposición entre experiencia colectiva y experiencia individual. La primera se corresponde con la idea de la Prehistoria republicana, también vista, con reservas, como el universo de la memoria semiótica; la segunda, en cambio, con la historia, ligada a la memoria simbólica ${ }^{10}$. Como hemos señalado, ambas se corresponden con la noción de memoria cultural que las reúne como resultante de la clave narrativa.

La memoria posee, sin lugar a dudas, un estatuto matricial. De este estatuto prevalece como fundamento interior el proceso de presentificación (Vergegenwärtigung), que polariza los acontecimientos en historia anterior y posterior y singulariza la historia; la historia (que no es ciencia porque en sí misma es una forma de recuerdo por el archivo), mediante la flexión metanarrativa, reifica la memoria [Ricoeur, 2000; Hutton, 1993], pero es la primera la que le otorga su cualidad final: el sustrato subjetivo a partir de las dos dimensiones complementarias, según señalara F. Hegel, de historia rerum gestarum y res gestae. Narración y acontecimiento se conjugan en la necesaria aparición de la Ley estatal que los organiza, los jerarquiza en relatos basados en la heroicidad o en el rescate de la microhistoria, y les da una entidad, mediante la función conmemorativa, de loci de memoria. El estatuto matricial de la memoria en relación con la historia estaría en el eje de la narración como organización necesaria y determinante de lo temporal.

\section{LAS NARRATIVAS IDENTITARIAS: EL SENTIDO CONMEMORATIVO DE LA HISTORIA}

«El hombre que oye, que es testigo, que ve, que sabe y que no habla...es culpable» Levítico.

En un trabajo de reciente publicación, E. Runia ${ }^{11}$ remarca la importancia en los relatos traumáticos de cómo narrar la experiencia de la memoria traumática en un sentido que no es ya, para la filosofía de la historia, simplemente cuestión de archivología o producto del morbo. El

10 La distinción que, partiendo de J. Lacan, utiliza J. Kristeva se basa en la diferente función, dialéctica, entre una memoria simbólica de la realidad y una semiótica de la misma.

11 Burying the dead, creating the past. Ponencia presentada en el II Congreso Internacional de Filosofía de la Historia. Reescrituras de la Memoria social. Buenos Aires, octubre de 2006. 
discurso de la Historia, especialmente para la narración de eventos traumáticos, debe necesariamente volverse literario porque la conmemoración deviene inevitablemente retórica. Allí donde debiera triunfar el silencio del no decir, muy parecido al que propone Adorno luego de Auchwitz o Semprún en La escritura o la vida, la Historia necesita representar actancialmente la memoria traumática. Esta conciencia histórica se corresponde con un deseo de conmemoración. Aquí debe entenderse que la oposición planteada entre memoria e historia, se sitúa en el debate entre Historia y conmemoración. Nuestra segunda antítesis afirma, entonces, que el discurso de la historia funciona en el despliegue opositivo de estos dos términos. Contra la práctica positivista de la historia, la conmemoración implica siempre la valoración de actos humanos contra actos de Dios o propios de la naturaleza, como los desastres naturales. Porque en estos actos es donde los sujetos se reconocen como humanos. La habilidad para la puesta narrativa de la historia consta, según E. Runia, de tres cuestiones: aquellas cosas de las que nos enorgullecemos, aquellas de las que nos avergonzamos y, por último, aquellas transformaciones miméticas a partir de las cuales nos embarcamos en lo inimaginable. Centrándonos en este último elemento, la historia narrativa nos devolvería a esa hermosa metáfora que acuñara Humboldt, donde abandonamos los palacios y regresamos a nuestras «homely huts» porque el autoreconocimiento nos lleva a ese común denominador llamado humanidad. El famoso memory boom es un fenómeno único sólo si tenemos en cuenta la ambigüedad de no poder distinguir en el siglo XX entre la memoria por escasez y la memoria por exceso. La segunda supone un problema psicológico que consiste en reponer y superar el trauma, la primera, por el contrario, es propia de una nostalgia ontológica (Ontological Heimweh) que necesariamente lleva a la actividad histórica por la misma necesidad de rememoración. De esta manera, Runia llega a la conclusión de que la escritura histórica responde a nuestra facultad de externalización. Esta facultad vuelve a desplegar la idea que propone G. Vico a propósito del sentido de lo humano, por cuanto una de las externalizaciones básicas y más fundamentales es el ritual del entierro. Explica G. Vico:

\footnotetext{
Dicha humanidad tuvo sus comienzos en el humare, "sepultar» [...] por lo que los atenienses, que según cuenta Cicerón, fueron los más civilizados de todas las naciones, fueron los primeros en sepultar a sus muertos [Vico 1995: 271].

Finalmente, cuán importante principio de la humanidad son las sepulturas, se constata si se imagina un estado salvaje en el que quedaran insepultos los cadáveres humanos sobre la tierra para ser pasto de cuervos y perros [...] y que los hombres, como puercos, comieran bellotas, recogidas entre los cuerpos putrefactos de los muertos [Vico 1995: 160].
} 
En este sentido, el entierro supone dos motivos de relevancia: la cercanía y la perpetuación. El muerto es un modelo del cruce entre presente y pasado y es un modelo de no olvido a futuro. El muerto genera tradición y es, por esto mismo, que el muerto se vuelve la metáfora esencial del discurso de la historia. Hacer historia supone ese ritual del entierro que nos lleva a construir el pasado a partir de las representaciones narrativas. La historia tiene, luego, una utilidad. Como señala R. Belvedresi' ${ }^{12}$, la misma sirve 1) para no repetir el pasado; 2) para dar cuenta del progreso humano, y 3) para justificar un determinado estado de cosas. Para el caso que nos ocupa, el escrito histórico debe moralizar para advertir acerca de los errores del pasado; debe, también, dar cuenta de cómo ha evolucionado eso que se da en llamar, en nuestro análisis, por ejemplo, España y memoria discursiva republicana. Y, por último, debe legitimar -y es aquí donde entra en juego la aplicación necesaria de la representación o razón imaginativa a través de la ideología - el estado democrático en detrimento de los nacionalismos fascistas. En este momento entran en juego las luchas por el poder de la representación y de las versiones interpretativas que más se ajustan al sentido histórico que haga justicia al pasado. Para el caso que analizaremos, basado en un escrito histórico que pretende instruirnos acerca de la guerra civil, la noción de justicia es central, ya que representa la lucha de poder entre dos memorias discursivas: la republicana y la nacionalista.

\subsection{ABUSOS DE LA MEMORIA: DISCURSO, UTILIDAD, DEBER.}

Una de las preocupaciones centrales que subraya T. Todorov en Los abusos de la memoria tiene que ver, por un lado, con los usos y abusos que de la memoria colectiva e incluso popular han hecho los regímenes totalitarios del siglo XX y, por el otro, con el problema de la utilidad de la memoria, con el para qué social y moral de la memoria y el olvido. Volvemos sobre este último par dicotómico, al menos en apariencia, puesto que el olvido es parte indisociable de la memoria y viceversa. $Y$ ya que la memoria funciona como una especie de verdad histórica, es comprensible que esté revestida por luchas de poder. En el caso de España, tras la guerra civil, el olvido tuvo su asiento en la selección de una memoria imperial y épica, en la censura de lenguas opuestas al castellano castizo así como en la desaparición de toda huella de una me-

12 Consideraciones acerca de la utilidad de la Historia. Ponencia presentada también en el II Congreso Internacional de Filosofía de la Historia. Reescrituras de la Memoria social. Buenos Aires, octubre de 2006. 
moria republicana, categorizándola y unificándola, incluso, bajo el término despectivo "rojo". La supresión y la conservación establecen una relación dialéctica; ahora bien, cuando se decide qué se suprime y qué se conserva, nos encontramos frente a decisiones políticas y es necesario analizar sus causas, que responden a una utilidad de la memoria ${ }^{13}$. Señala T. Todorov que, cuando el acontecimiento del pasado tiene naturaleza trágica, el derecho de saber la verdad o las verdades se vuelve un deber, que es el deber del testimonio. Tras la muerte de Franco, ese deber se tradujo en la emergencia del género testimonial, autobiográfico, al que se sumaron numerosos simposios, encuentros y tertulias cuya función era la de rescatar las memorias, las verdades ya no sólo de la guerra, sino de la dura postguerra, con los exiliados, los maquis y los topos. Podríamos decir que desde 1939, año de la victoria, el lugar de la legalidad democrática, con su lógica contractual, quedó anulado en pos de una legitimidad que proviene ante todo de la tradición imperial. Así, las leyes del franquismo reposaban en la supresión de la memoria del republicanismo liberal y en la conservación de la memoria de Primo de Rivera y los Reyes Católicos. Ahora bien, si estos usos corresponden a la llamada memoria oficial, ¿cuál es el criterio por el cual distinguimos entre su buen o mal uso? Un criterio posible es aquel que opone la condición de humanidad; es decir, si el criterio es anular la memoria vencida por medio de la guerra, claramente, catalogaríamos la acción como un mal uso de la memoria. Pero también podemos tener en cuenta el criterio que analiza el carácter del testimonio. Los acontecimientos pueden ser leídos o bien de manera denotativa o literal, como prefiere T. Todorov, o bien de manera connotativa o ejemplar. La memoria literal refiere a su significación denotativa; es decir, no buscar en sí misma moralizar y tiene carácter intransitivo, puesto que prevalece en su literalidad. La regla que lo determina es la de la contigüidad entre el acontecimiento del pasado y el momento del tiempo presente. Es un relato individual y que es contenido en una esfera privada de comunicación. Se aleja de las implicancias sociales y su sentido puede restringirse a la metatextualidad, justamente por ser tomado como una singularidad.

La memoria ejemplar, en cambio, si bien no niega la individualidad del relato testimonial, tiene una función inclusiva, puesto que la integra al conjunto de singularidades como un

$13 \mathrm{Al}$ respecto rescata T. Todorov la implicancia de la democracia frente a los totalitarismos nacionalistas: «Ninguna institución superior, dentro del Estado, debería poder decir: usted no tiene derecho a buscar por sí mismo la verdad de los hechos, aquellos que no acepten la versión oficial del pasado serán castigados. Es algo sustancial a la propia definición de la vida en democracia» [Todorov 2000: 16] 
punto de vista que entra en intersección con una generalidad. El testimonio, en este caso, busca patrones similares que ayuden a comprender un acontecimiento traumático aunque sus agentes y algunos detalles sean diferentes. Esta memoria no rige el espacio de lo privado sino el de la esfera pública; se vuelve, inevitablemente, un exemplum ${ }^{14}$ del que se extrae una lección tanto para el presente como para el futuro. El pasado, entonces, adquiere una función social, ya que brinda parámetros del buen actuar apoyándose no en la contigüidad sino en la semejanza, dada por recursos analógicos. La primera, como señala T. Todorov, porta riesgos porque tiende a perderse en un relato único al que, incluso, se podría justificar; la memoria ejemplar, en cambio, libera porque incluye al otro. Su transitividad es lo que lleva a entenderla no en términos Ilanos de «mera descripción» de un conjunto de eventos del pasado sino, por el contrario, en un relato que hace justicia y obliga al compromiso. Por eso la ley es impersonal, justamente porque hace de un relato subjetivo una generalización, donde importa que el acontecimiento, en tanto sea juzgado, no se repita.

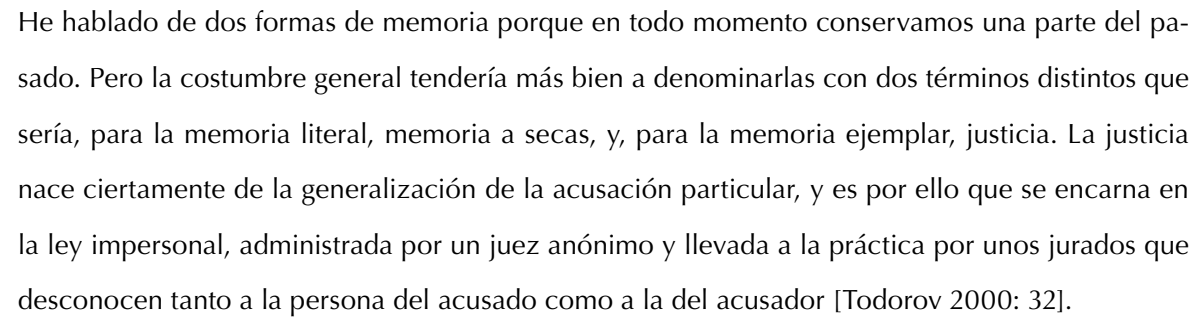

De esta forma, tomar un acontecimiento de manera singular y superlativa no deja ver qué características comunes comparte con otros presentes; así se pierde la capacidad de aprender del pasado para resolver acontecimientos presentes. Así las cosas, la recuperación del pasado no está buscando la verdad — cuestión que se reduce a la verosimilitud— sino al bien. Así, no habrá un exceso de memoria en oposición a una supresión de la misma sino, por el contrario, entre un buen o mal uso en ambas. El mal uso está ligado en los regímenes totalitarios a estrategias concretas de control social y prohibición. La segunda consiste en la desaparición de huellas: monumentos, aparatos de Estado, cadáveres, documentos, etc. para imponer otros bajo la insignia oficial. La segunda, propiamente de control, se basa en la intimidación de la población y la prohibición de adquirir o hacer circular determinada información. Más aún si lo pensamos en la

14 El género exemplum, originariamente medieval, debía dejar una enseñanza o moraleja de fuerte contenido ético o moral a propósito del caso presentado. 
etapa de postguerra, donde la misma autarquía subrayaba la clausura. Otra estrategia consiste en el trastrocamiento de la realidad mediante eufemismos: las alusiones a una cruzada, el término rojo, la revolución o los paseos. Por último, la mentira entendida como propaganda: los grandes afiches mostrando una España una o los XXV años de paz mientras se seguía castigando a los republicanos. Si los acontecimientos dejan dos tipos de huellas, unas denominadas «mnésicas» y otras «materiales», existen procedimientos para hacer revivir el pasado en el presente: 1) El establecimiento de los hechos del pasado supone una construcción basada en la selección y en la jerarquización. 2) La construcción del sentido es inherente al relato testimonial por cuanto los acontecimientos deben ser interpretados. Aquí no se trata de comprender como medio para justificar, como decía P. Levi, sino de analizar el mal para llegar al bien ${ }^{15}$. No se produce una verdad sólo por adecuación, como en el primer nivel, sino por desvelamiento, lo que ahonda en la psicología social. Es por eso que es intersubjetivo y nunca referencial. 3) La puesta en servicio de la memoria corresponde al reconocimiento y la interpretación. Los acontecimientos son relatos; pueden ser heroicos o victimistas.

Sobre este último punto nos gustaría realizar una breve reflexión. El estatuto de víctima, sin lugar a dudas, es el lugar privilegiado del relato testimonial. El relato heroico es, generalmente, propio del discurso histórico oficial. La víctima tiende, comúnmente, a la protesta y al reclamo y es más probable que la memoria juegue un rol mucho más central que en el relato histórico. Este último, mientras intenta la objetividad deja para el testimonio el desarrollo intersubjetivo. T. Todorov [2000b] lo explica mediante la analogía de la pasión de Cristo por cuanto la víctima necesita del reconocimiento de los demás pero también de la idea de misión moral que conlleva el sufrimiento, que ya no sólo se sabe individual sino social. Al respecto tres son los grandes discursos que utilizan las huellas del pasado para influir en el presente: el del testigo, el del historiador y el del conmemorador [op. cit: 155]. El discurso del testigo es aquel cuyo sujeto productor reúne los recuerdos para darse una identidad. Es un trabajo individual que puede estar o no acompañado de huellas materiales. Es, en este caso, metatextual; no hay quien condicione la tarea porque nadie puede refutar un acto singular. El historiador, como hemos analizado ya,

15 Explica T. Todorov: «Todos los hombres son potencialmente capaces del mismo mal, pero no lo son efectivamente, pues no han tenido las mismas experiencias: su capacidad de amor, de compasión, de juicio moral ha sido cultivada y ha florecido o, por el contrario, ha sido ahogada y ha desaparecido» [2000b: 151] 
representa a una disciplina y busca un discurso asimilable a una verdad, aunque en realidad apunte a una adecuación verosímil. Busca la construcción de sentido objetivo y se opone al testigo sólo en la esfera y en la construcción de sentido.

Ahora bien, cuando el discurso del testigo merezca ser tenido en cuenta en la esfera pública se transformará en discurso testimonial. Ambos se enriquecen, puesto que el testimonio se jerarquiza y legitima por el punto de vista, mientras que el discurso histórico lo ordena y lo hace inteligible. Por último, el discurso del conmemorador comparte con el del testigo el interés propio de su tarea pero, al igual que el del historiador, su discurso se produce en la esfera pública y se presenta con un énfasis mayor de verdad que el frágil discurso testimonial, a la vez que refleja la imagen de una sociedad. Los aparatos ideológicos de Estado como la escuela o los medios de comunicación son los espacios por excelencia para la difusión de este tipo de discursos. La conmemoración simplifica nuestra visión del pasado mientras que la historia la complica. AqueIla busca venerar héroes y aborrecer tiranos y así jugar un rol político en el presente, mientras que la historia sólo accede a su estatuto o pretensión de objetividad sin explicitar intereses. En el apartado subsiguiente profundizaremos en las características de los discursos de memoria, prestando especial atención al carácter tanto ético como moral.

\section{USOS CONMEMORATIVOS DEL TESTIMONIO}

«Para escribir este libro he usado el lenguaje mesurado y sobrio del testigo, no
el lamentoso lenguaje de la víctima... creo en la razón y en la discusión como
supremos instrumentos de progreso y por ello antepongo la justicia al odio» supremos instrumentos de progreso y por ello antepongo la justicia al odio»
[Levi 1986:185]

Primo Levi es el testigo por excelencia. Su relato de la experiencia del Lager $^{16}$ no tiene como punto central contar la historia del sobreviviente sino, por el contrario, dar testimonio. No busca posicionarse como víctima; busca la razón de los hechos y la discusión acerca de las víctimas y los victimarios; busca un lector a quien concientizar sobre los males del Holocausto. En esas reflexiones encontramos un punto de partida para analizar la experiencia del testigo del periodo franquista por su intención educativa. La amenaza de los totalitarismos necesita de ese desciframiento del mal, de la descomposición del recuerdo para integrarlo al tamiz de la me-

16 Lager fue un término usado para definir los asentamientos en los campos de concentración del Holocausto. En su campo semántico referido a lo bélico admite las definiciones de guarida y campamento, entre otras. 
moria, porque dicho mal perdura como amenaza en el presente, no se consumió en el pasado. Y es el factor educativo lo que a ambos testigos les interesa, ya que allí no hay engaño. En la veta subjetiva, sin el disfraz de la objetividad historiográfica, están los verdaderos relatos. Y es la conmemoración de la víctima lo que ambos buscan a partir del testimonio.

En principio, el relato testimonial busca clasificar por definición. Para Primo Levi la palabra del superviviente limita con el silencio del musulmán. Ese límite transita una verdad subjetiva. Los judíos llamaban musulmanes a quienes tocaban fondo y no volvían o volvían mudos.

Su vida es breve pero su número desmesurado; son ellos los müselmänner, los hundidos, los cimientos del campo; ellos, la masa anónima, continuamente renovada y siempre idéntica, de no-hombres que marchan y trabajan en silencio, apagada en ellos la llama divina, demasiado vacíos ya para sufrir verdaderamente. Se duda en llamarles vivos: se duda en llamar muerte a su muerte, ante la que no temen porque están demasiados cansados para comprenderla [1986:96]

El deterioro físico y psíquico de la corporeidad del musulmán es, sin duda, indicio de su degradación moral. Por eso es un «testigo integral», aquel que en su totalidad ha sido marcado por el mal y cuya actualidad lleva a la rememoración del mal. Es la presencia de la imposibilidad, aquel que sabe pero es incapaz de comunicar. Para eso está el testigo que hace justicia de la memoria del mal para lograr el bien. En el relato de esta puesta en narración del testigo habría que distinguir, sin embargo, tres estadios ${ }^{17}: 1$ ) El nivel de lo autobiográfico o del sujeto empírico. 2) La identidad narrativa, que es la construye el imaginario social necesario para la justicia. 3) La identidad meramente del sujeto autor, que organiza e incluye los dos niveles anteriores [Robin 1996: 61]. Esto hace del relato testimonial un discurso puesto en función del conocimiento. La comprensión a la que hace referencia P. Levi supone un conocimiento del origen, de las causas, para prevenirlo en el presente. Por eso, Benet es el testigo directo del franquismo e indirecto de la guerra. No obstante, el relato moral de esta última invade constantemente el testimonio del presente. El deber de conocer implica el uso de la subjetividad. Deben ser los propios sujetos en su función de testigos quienes brinden un testimonio porque, de esa manera, humanizan al deshumanizado por el mal de los regímenes totalitarios. Si la víctima, especialmente figurada

17 Régine Robin centra su interés en el problema de la identidad y en su transformación frente a la pérdida; en este caso, la nueva identidad del testigo o de la víctima, que no permanecen estables. Cuando ese terreno se encuentra amenazado, ahí se afirman las identidades narrativas [Ricoeur 1985] con marcadores de verdad, adecuación o pertinencia para lograr un efecto de realidad. 
por el musulmán, se encontraba absolutamente deshumanizada por lo tecnológico del exterminio y la degradación moral que supuso, es un deber del testigo que puede comunicar hacer del recuerdo un testimonio moral, porque así estará haciéndose cargo de la inhumanidad del otro y, con su voz, intentará devolverle la integridad moral y el estatuto de sujeto político. Una de esas estrategias es la de distinguir entre víctimas y verdugos: «No sé ni me interesa si en mis profundidades anida un asesino, pero sé que he sido una víctima inocente y que no he sido un asesino; sé que ha habido asesinos y no sólo en Alemania, ...y que confundirlos con sus víctimas es una enfermedad moral» [Levi 1986: 42].

Deberíamos entender, entonces, que la memoria histórica no consiste en ver cómo le fue a cada cual en la guerra civil o durante el franquismo, sino someter a discusión o, como quería Levi, a la razón, la reflexión política sobre una violencia pasada sobre cuyo olvido, o su elipsis, se ha construido el presente. Para lo mismo, la memoria es justicia, puesto que la reconstrucción pasa por la identidad colectiva; es decir, por una política que, alejada en nuestro caso del pacto de la transición, sea de reparación, reconocimiento y reconciliación. Y en el relato es donde entra en juego el lector. Para Levi, los jueces son los lectores. Memoria de la injusticia como condición de la justicia. Por eso, también para Benet el relato testimonial lleva a preguntarse con el lector por el período franquista sin alejarse del momento de producción de relato. Avishai Margalit [2002], luego de establecer una relación triádica entre recuerdo, interés y ética, se vuelca sobre el concepto de testigo moral, que es el que nos interesa en el análisis del relato testimonial, ya que es uno de los administradores del recuerdo colectivo. El testigo moral es quien experimenta los sufrimientos de manera propia u ocular y quien se encuentra en riesgo. En el caso del relato que analizaremos en el siguiente apartado se dan las características de «testigo» $y$ «sujeto moral» sin ser el relato producido por un «testigo moral». Este no es quien porta la esperanza en su sentido teológico sino quien, a diferencia del mártir, debe sobrevivir para así poder relatar un estado de acontecimientos, hacerlo inteligible y legitimarlo; de ahí el uso de la primera persona para poner el énfasis en la experiencia de la exposición frente a ese mal. La autenticidad en la narración hace que en el relato benetiano se conjuguen la representatividad de una comunidad y el deber moral de la enseñanza del mal. La representatividad está dada por 
su pertenencia generacional, la de los intelectuales del medio siglo, en cuanto al deber moral ${ }^{18}$, implícitamente narrado, se encuentra en la prevención contra los totalitarismos, que parte de un interés tanto personal (Anteilnahme) como objetivo (Interesse). Ambos debieran ser correlativos para lograr el bien, puesto que todo objetivo tiene su raíz personal para volverse auténtico. Así, en los relatos testimoniales en los que Juan Benet se ubica como un testigo moralizador de la etapa franquista, vemos cómo oscila entre los territorios de la moral y de la ética para alertar sobre el mal del nacionalismo católico.

Manuel Tuñón de Lara, que pasó más de treinta años en el exilio, recordaba en su «Última clase magistral» que para Bloch «la historia es la ciencia del devenir de los hombres en el tiempo, que viene de ayer y va hacia mañana». Eso obliga a los pueblos a recuperar su memoria colectiva cuando ésta les ha sido arrebatada, ocultada o falsificada. España ha pasado por eso como otros pueblos, como el pueblo alemán, como ha pasado con los países del Este, etc. [De la Granja y Tapia 1993: 454]. Pero España presenta unas variantes distintivas ya que el triunfo en 1939 del fascismo nacionalista y católico fue conociendo varias reformulaciones, pero siempre manteniendo la imagen y el poder de Francisco Franco. Esta variante vulneró en su momento, y lo sigue haciendo hasta hoy, la función — según Javier Tusell— de la memoria «como elemento que configura espiritualmente una sociedad, y, además, es indicio de los cambios que en ella se producen». Y añadía Tusell que la guerra civil contribuyó durante años a mantener al régimen y sustentar la Transición recordándole a la clase política que se podía producir nuevamente un conflicto civil como el de los años treinta [Tusell 2002]. Sobre el pacto de olvido de la Transición — que para Max Aub significaba, negativamente, contemporizar ${ }^{19}$ - los escritores buscaron la construcción del pasado, la activación de la memoria, ya sea con la contienda en primer plano o como telón de fondo, con un condensado como Región ${ }^{20}$, o con la labor de recordar en rela-

18 Nos basamos en la distinción de A. Margalit entre moral y ética. Mientras la primera se corresponde con lo que el autor Ilama «relaciones sueltas», no marcadas por una cercanía; la segunda se corresponde con las Ilamadas «relaciones estrechas». Para lo mismo se basa en la parábola del buen samaritano [Lucas 10, 29-37] a partir del término «prójimo».

19 «La actualidad es gran comedora. Sin embargo, el hombre lo es porque, entre otras cosas, no olvida. Pero la política le lleva mil veces a borrar palabras y hechos de la memoria porque ésa es la medida de las conveniencias. Los buenos políticos suelen tener mala memoria; mas el escritor vive de ella y por ella se hace. Divergencia fundamental que puede explicar el fracaso de tantos escritores, si lo son de veras, metidos a políticos. Las obras sólo quedan de la voz de la fama; y nosotros luchamos contra el olvido. Los políticos llegan al recuerdo — que es la Historia- a fuerza, muchas veces, de lo que Ilaman contemporizar; es decir, ser contemporáneo, olvidar lo pasado con tal de asegurar el paso inmediato, transigir, condescender, mentir. No son estas prendas del escritor, como no sea por juego» [Aub, 2002: 134].

20 Benet construye un espacio imaginario llamado Región que funciona, en realidad, como condensado ideológico más que como cartografía, de la memoria discursiva republicana. Ver: HL. 
tos testimoniales. A diferencia de toda Europa, donde el mal de los fascismos se hizo evidente, en España quedó oculto por un régimen que duró casi cuarenta años. Por eso los testimonios se orientan al bien, a la manera aristotélica, a la compulsión del testimonio. Porque quizás, contradiciendo a Theodor Adorno y apoyando la tesis de Günter Grass, es una obligación seguir escribiendo, continuar recuperando la memoria del pasado traumático para que no acabe nunca y sirva de alerta en el presente y el futuro. A continuación, analizaremos el caso de testigo moralizador en un relato testimonial de Juan Benet que recupera la memoria de los vencidos, no sólo los del campo intelectual —Baroja, Caneja— sino aquellos propios de la microhistoria —la gente común— durante el franquismo, como aporte fundamental a la memoria colectiva.

\subsection{LAS MEMORIAS DE "LO INVICTO”: OTOÑO EN MADRID HACIA 1950}

El debate que tras la muerte de Franco no se pudo realizar —empañado por la ficción superadora de la Transición — se vio intensificado por el boom de relatos testimoniales. Emilio Silva escribía en El País del 15 de diciembre de 2002 que la recuperación del pasado está ligada al reconocimiento de las víctimas y al conocimiento del hecho. ${ }^{21}$ Estas relaciones marcan la necesidad de una generación de rescatar, de dialogizar la memoria, la identidad de aquello que ha permanecido invicto. Como explica Francisco Caudet [2008], no basta con desenterrar muertos, asignarles un nombre y pasarlos a la memoria del pasado. Los muertos tienen familia y proyectos políticos opuestos al régimen franquista del nacionalismo católico. Invicto en el sentido que un conjunto de relatos puede tener hacia 1987. Acumulación de piezas aparecidas antes en libros colectivos y papeles periódicos, pese a la cronología intermitente en que fueron escritos, entre 1972 y 1986, a la consideración de Otoño en Madrid hacia 1950 (OM) como un libro menor. Madrid y San Sebastián, la guerra y la sentimentalidad durante el franquismo: los recuerdos de «El Mirlo Blanco», Pepín Bello, Dominguín, la tertulia, Baroja, Caneja. Invicto en el retrato ético

21 «El proceso de recuperación de la memoria y del conocimiento de la dura realidad de la guerra civil y del franquismo evidencia la necesidad que tiene la sociedad española de conocer su historia reciente. El impacto causado por la exposición sobre el exilio, realizada recientemente en Madrid (Exilio 2002), la apertura de las fosas comunes o el documental sobre los niños secuestrados a las presas republicanas, es un reflejo del desconocimiento generalizado de esa parte de la historia. Amplios sectores sociales se encuentran sorprendidos por lo que están conociendo, y los que ya lo conocían y lo padecieron están necesitados de reconocimiento, de ver ese reflejo de sus vidas en espacios públicos. Si no seguimos el proceso de países como Alemania o Francia en la revisión del pasado relacionado con el fascismo, y no se habla y se cambia el significado de ese pasado y de nuestra relación con él, seguirán en nuestra identidad y habitando en nuestro inconsciente colectivo efectos que causó directamente la dictadura. [Silva, 2002; el subrayado es nuestro] 
y moral de los tipos humanos que han permanecido en la memoria, victoriosos por fuera de la memoria oficial. En su doble significancia, también por ser la republicana una memoria que ha quedado intacta o, como diría J. Benet, en penumbras. OM desvela la memoria de la España franquista, una memoria que alejándose de los grandes relatos devuelve la mirada a la microhistoria, a la intrahistoria de sujetos que han de volverse históricos. El testimonio en ese cruce entre la historia y la memoria, inventa porque, como explica Benet «no obedece a otra regla que a la de romper el círculo de lo inventado». Ese círculo del franquismo se rompe con la frontera que va desde lo privado a lo general. Allí, la voz del testigo se materializa para ser una voz entre las voces de la memoria colectiva.

\subsubsection{PENSAR LA HISTORIA, ESCRIBIR LA MEMORIA}

«Un pequeño volumen de memorias en cierto modo contrapuesto a mi — por

el momento vigente- propósito de no escribir nunca memorias ni diario ni cosa parecida"

[Benet 1987: 13]

La memoria, como describe J. P. Vernant ${ }^{22}$ supone un viaje al pasado, pero ese pasado, como canta Mnemosine, es siempre una mirada sobre lo invisible y una geografía de lo sobrenatural. Este carácter ficcional de la memoria relatando el pasado, de la memoria buscando el pasado desde esa reminiscencia aristotélica actualiza el debate inevitable acerca de la escritura de la historia y, más específicamente, del problema epistemológico de la producción de sentido en la hermenéutica de los relatos del yo. Otoño en Madrid hacia 1950 es, sin duda, un conjunto de relatos que intentan explicar la historia de la inmediata postguerra franquista, es decir, un programa de textos literarios donde la puesta en escena de un yo rompe a la vez que inaugura el relato fundacional de otra historia, esa que quiebra la tesis 1.5 con la que F. Ankersmit anuncia la muerte de la hermenéutica epistemológica para dar paso a la hermenéutica analítica. En este sentido, el problema central es el que está implicado en este debate y que ha tenido en España, respecto del boom de las narrativas históricas, un anclaje decisivo para reflejar, en realidad, un debate más profundo: el de una historia que nunca termina de contarse, que sigue eligiendo sus referentes, sus espacios y sus memorias, que ya no han de ser ni oficiales ni unitarias sino

22 J. P Vernant en «Historia de la memoria y memoria histórica» desarrolla la concepción de la memoria ligada a la creación (poiesis), y aquí es donde la narrativa cobra importancia por su carácter ficcional. 
dialectales, heterogéneas y varias. El problema central es entender que el referente fáctico es también una construcción del punto de vista, que la noción de verdad irrevocable se anula en la polisemia intrínseca a la memoria y que las imposibilidades de ese mismo referente son, ante todo, posibilidades discursivas.

El debate de la historia y, por ende, de la memoria verdadera, encuentra en este texto de Juan Benet una posible explicación que, además de ofrecer un punto de partida genérico, brinda — y es esto lo fundamental— un panorama ideológico de recuperación del republicanismo que estará atravesada por lo que, para algunos teóricos, implica la influencia de la concepción de la postmodernidad: en la muerte del sujeto y de la representación (Lyotard), en la muerte de la historia (Fukuyama), en el imperio de la sincronía y la simultaneidad (Jameson), en la disolución de la obra-texto (Derrida) y en la polisemia interpretativa (ECo).

Sin embargo, se mantendrá como problema central la recuperación de la memoria y la tradición valorizada del republicanismo frente a la tradición criticada del franquismo. Estos polos marcan todo el trayecto narrativo que se verá configurado en tiempo y espacio en las novelas a partir de la reformulación amplificatoria que proporcionan los ensayos sobre la memoria, la historia, la idea de escritor y la literatura, junto con las problemáticas en torno de la moral, la ética y la memoria colectiva.

Es por eso que nos interesa esa relación entre los ensayos, incluyendo los relatos testimoniales tanto como las novelas. Si con sus ensayos históricos Benet explicitaba desde su lugar de enunciador objetivo (con ayuda de las parentéticas de matiz irónico) la actualización de la memoria histórica, en OM, mediante la presencia del sujeto en primera persona subjetiviza el relato para volverlo experiencial, siendo su cercanía a los hechos de matiz ético. Tres ejes resultan esenciales: el anclaje temporal de 1950, los condensados ideológicos república, franquismo, guerra civil en tanto servirán para explicar los estadios de prehistoria e historia en las novelas y, por último, el marco espacial, la ciudad madre, Madrid, que cubre y despedaza, esos topoi discursivos que señaliza las huellas de una ciudad que ha sido quebrada en su dialéctica interno/ externo y público/privado. 
3.1.2. 1950

«...Y sobre todo el vértigo del tiempo, el gran boquete abriéndose hacia dentro del alma...»

[Gil de Biedma 1975 Las personas del verbo: 37]

Los años de la inmediata postguerra encuentran su anclaje en lo que funciona como un fuerte quiebre respecto de la ideología republicana. La propuesta del racionamiento ${ }^{23}$ es central como productora de ideología y la ciudad franquista se escenifica como centro del control y el aislamiento. Señala M. Vázquez Montalbán que

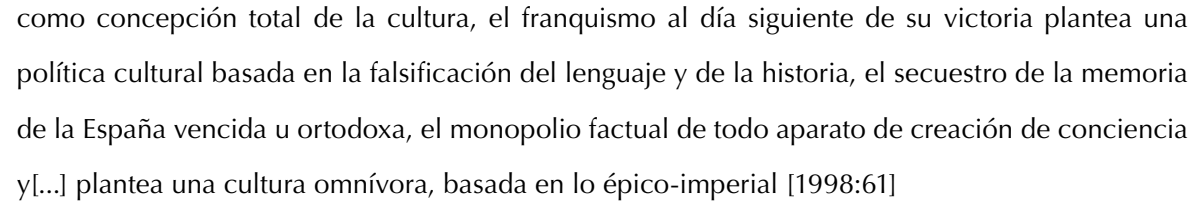

En este sentido, «Barojiana», primer artículo de la serie, ofrece la recuperación de la memoria de la generación del 98, y aquí el sentido de la historia y de la necesidad de historiar ${ }^{24}$ evidencia el primer gesto de la memoria discursiva republicana, con la que nos referimos a un conjunto de enunciados que la tradición de una ideología reformula en su historia. Frente a la construcción de héroes del franquismo, la perspectiva de la narrativa histórica de Baroja sirve a los efectos de rescatar la memoria inválida pero invicta de los no-héroes. El héroe sin grandeza, lo que lo vuelve común, la prosa sin brillo, lo que la acerca a los hombres y a la intrahistoria, de la que nos hablaba Unamuno, y que los textos de Benet, en ese juego de presencia-ausencia de la memoria, optan por rescatar del olvido, los referentes del republicanismo, mediante el recurso de la «presentización» como parte del preterizar, actualizando siempre un sentido presente a partir del argumento de la continuidad, donde la novela cobra especial atención por su detenimiento «entre dos cortaduras de tiempo $»^{25}$.

Al igual que en sus novelas, estos textos vuelven al leit motiv de la memoria porque es necesario ver los quiebres, ya que, como señala Bergson, «siempre es la parada lo que exige una

\footnotetext{
23 Carmen Martín (1999) en Usos amorosos de la Postguerra española (Madrid: Alfaguara) se refiere a la lógica de restricción y racionamiento en el primer período franquista como un ampliación de lo económico a lo sociopolítico.

24 Utilizamos historiar en vez de historizar, término que comporta, desde Mandelbaum, el sentido de analizar la historia desde sus propias condiciones materiales; en cambio, el término historizar, según Popper, siempre incluye la perspectiva a futuro, donde entra la conjetura.

25 Esta afirmación permite ratificar la idea de una división temporal entre una prehistoria y una historia que se le opone.
} 
explicación, no el movimiento». Esta parada, este quiebre en la memoria que supuso la guerra con la consecuente resultante del franquismo necesita explicarse una y otra vez. 1950 es quizás una posible explicación que funciona como eje para entender también la construcción de estos artículos, ya que ese año se dictamina la obligatoriedad del Documento Nacional de Identidad con la huella dactilar del pulgar, lo que suponía un control estricto del ciudadano español. Este quiebre, que deja de ser sólo fáctico, es funcional a los efectos de explicar su significación ideológica. Para lo mismo, el ethos discursivo que se elige es el del intelectual crítico quien, siguiendo los lineamientos de $\mathrm{H}$. White, utiliza como recursos tropológicos predilectos, la ironía y la metáfora. Para el anclaje temporal, 1950 y, en especial, los años de transición, determinados hacia 1946, en que tienen lugar los relatos sobre Baroja y Caneja, encuentran su oposición en los usos irónicos respecto del Régimen franquista que, en la mayoría de los casos, aparecen en posición paratáctica, para resaltar la presencia de un sujeto enunciador que deja en claro su opción ideológica, tal como hiciera en dos ensayos anteriores: QFGC y LCGC, el primero de 1975, año de la muerte de Franco; el segundo, de 1986. Los usos metafóricos tienen siempre su connotado en la construcción discursiva del republicanismo frente al Régimen, cuyos signos eran siempre asociados al autoritarismo y la decadencia:

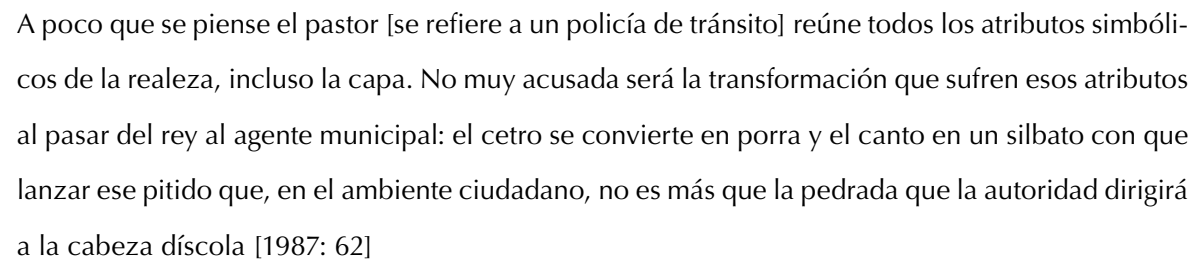

De esta forma, los artículos focalizan en la recuperación de una memoria discusiva republicana cuyos héroes son, ante todo, los antihéroes de la Historia oficial, de la España una que es, en realidad, una España dialectal. Este dialectismo funciona contra el aparato del Estado censor franquista mediante la posibilidad del rumor colectivo, que Benet ilustra a partir del análisis de dos planos de la información: uno oficial, engañoso; otro, el del rumor subversivo, «exponente de una realidad que todos los días estaba a punto de romper el frágil cascarón de la censura» [23]. Las memorias de este relato se articulan mediante procesos de metaforización, generalmente, las metáforas de la enfermedad, como crítica a la España franquista. En un nivel implícito, la estructuración del texto como una «galería de figuras» lo aleja de la intencionali- 
dad semántica de todo relato testimonial, que se centra sobre el yo, aunque lo mantenga como hilo conductor. Como explica P. Ricoeur [2000], en correspondencia con el pensamiento de M. Halbwachs, sólo se recuerda desde el punto de vista social: «Nous dirions volontiers que chaque mémoire individuelle est un point de vue sur la mémoire collective, que ce point de vue change selon la place que j'y occupe et que cette place elle-même change selon les relations que j'entretiens avec d'autres milieux».

\subsubsection{REPÚBLICA, FRANQUISMO, GUERRA CIVIL}

Siguiendo la tesis de I. Lotman [1979] ${ }^{26}$, la memoria no sería ese depósito pasivo de la historia oficial sino que contendría, además, la emergencia diseminada de los testimonios y los relatos de esos dialectos de memoria. Si la cultura oficial, durante la dictadura de Franco, provocó claramente la declaración de ruptura con la República, la emergencia en estos relatos provoca el quiebre ideológico resultante en la ficción como ese entramado que permite el sentido histórico. Es por eso que el testimonio, como advertimos anteriormente, permite operar el desplazamiento de lo privado a lo público y en ese desplazamiento reconocer lazos de identidad. La cultura, señala I. Lotman, es una inteligencia y una memoria colectivas ${ }^{27}$. Por lo tanto, para su recuperación, dicha memoria, además de informativa, puede resultar claramente creativa.

Tal es el rol del arte que, además, Benet supo aplicar a las artes plásticas con la técnica del collage, como también lo hiciera a nivel narrativo ${ }^{28}$. Definir, entonces, la cultura como memoria de la colectividad implica plantear «el problema del sistema de reglas semióticas según las cuales la experiencia de vida del género humano se hace culturas». [Lotman 1979: 71]. Todo acontecimiento que sea concebido en primera instancia como existente necesita ser identificado con un elemento específico perteneciente a la lengua del mecanismo memorizante.

Desde esta perspectiva, toda cultura se estructura, ante todo, en un sistema de comunicación altamente socializado. Por consiguiente, aquellos símbolos que se tomen serán los que respondan a una memoria específica, que no está dada por elección sino por historicidad. Así

26 Tomamos a I. Lotman por ubicar el análisis de la memoria social dentro de una coyuntura mayor como la Cultura, desde la semiótica cultural.

27 Ver: «La memoria a la luz de la culturología».

28 «Et in Arcadia ego» tanto como «Ensayos de la catástrofe», la primera de 1992 y la segunda de 1984, son algunas de las obras pictóricas de J. Benet de contenido histórico y acerca de la memoria. 
termina el relato testimonial; con al figura de L. Martín Santos, preguntando «¿a dónde me llevan?». Allí permanece el sentido colectivo de las «memorias» en OM, donde la transmisión de la memoria siempre se hará por selección y relevancia para el momento presente.

En este sentido, es necesario que cada relato tenga su Walpurgisnacht ${ }^{29}$, puesto que, según la teoría de L. M. Santos, toda obra que se precie ha de tenerla. Se trata de la necesidad de la vuelta al pasado, de que todo texto se interrogue sobre el pasado y la memoria. No es casual que en Tiempo de silencio ese núcleo asome en la parte central del texto, parte que, vale aclarar, fue censurada. Y la memoria del republicanismo como la prehistoria que antecede a la tragedia de la Historia, dada por la guerra civil y perfeccionada por el franquismo, es también central en OM. Ese centro opera de manera irónica en «El Madrid de Eloy» y es el punto que revaloriza espacialmente a los espacios clandestinos de dicha ciudad.

Es por esto que los referentes del republicanismo son referentes de la memoria vencida pero invicta: la historia de la literatura, con los relatos de Baroja y Martín Santos y la historia del arte con el «rojo absoluto» de Caneja ${ }^{30}$, que cambió su forma de pintar al salir de la cárcel. Este quiebre en las formas, con un Baroja triste y desolado para quien se utiliza el subjetivema valleinclanesco, al igual que el relato de un Unamuno, que muere de tristeza al saber que había acabado la República, se nutre de otros relatos, de esos anónimos republicanos, como Benito, alcalde republicano de su pueblo toledano quien al regresar, salido de la cárcel, «no encontró un solo amigo, su mujer se había casado con el alcalde falangista y fue derecho a Carabanchel» [47], y la historia del filósofo con el ojo de vidrio que, en un gesto de valentía, recurrió a la policía: «Vengo a dar cuenta de mi desaparición, señor comisario» [55], o la figura de Eloy indagando el sistema en ese juego lingüístico que se titula en el artículo «El Madrid de Eloy», simulando el Paris de Baudelaire o la Praga de Kafka de manera irónica, puesto que España no había logrado estar a la altura de los demás países europeos. Esa huella del republicanismo que culmina con la figura de Luis Martín Santos, a quien también se menciona en los ensayos de PT y quien se configura con las construcciones nominales de Arcadia republicana o Hampa en plena transgresión irónica contra el franquismo, como esa utopía, que es necesario recuperar

29 Se llama así a las festividades en las que aparecían los muertos vivientes y se rendía culto a Baco, la memoria del pasado en un cruce carnavalesco

30 Es interesante ver en este artículo cómo no postula ningún extremismo. Para definir a los rojos, postula una escala de gradación, en tono irónico. 
para asignarle un lugar en la memoria de la Historia, que comienza con esa propuesta de una historia de la postguerra española a través del rumor, comentada en tantas tertulias clandestinas.

\subsubsection{LOS TOPOI DE LA HISTORIA}

«Esa historia que nadie sabía hacia dónde iba a dirigirse.»

[Benet 1987:17]

Los lieux de mémoire, según hemos definido de acuerdo con P. Nora, no sólo representan un cambio de miras y una renovación conceptual en el campo de la historiografía [Cuesta Bustillo 1998: 216-218] sino que, en tanto instrumento cognitivo, la noción de «lugar de memoria» se extendió más allá de los límites disciplinares y geográficos en los que se había gestado. Claro está que estamos trabajando con la construcción simbólica de los lugares de la memoria, con las voces diseminadas y los lugares discursivos que reconstruyen la memoria republicana. Aquí estos lugares se presentan como parte de una ciudad que expulsa, que es la negación de la naturaleza mediante el impulso deshumanizante del hombre. La ciudad estaba rota así como el «ecosistema intelectual», en términos de V. Montalbán, estaba destruido. El skyline de la ciudad franquista no coincide con el modelo que pensaron los griegos: la ciudad como una mujer en reposo que evoca a la Diosa Tierra, liberada de todos los trabajos y la acerca a la fecundidad. La ciudad moderna es el símbolo de la madre, con la bivalencia de la protección y el límite.

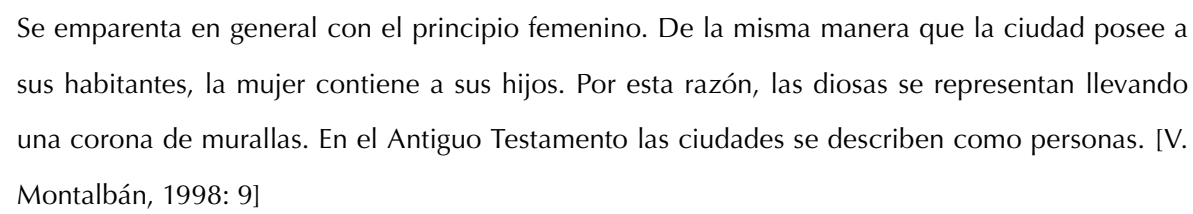

Pero ese skyline de la armonía griega es parte de la prehistoria republicana, de los recuerdos de infancia, donde la madre España no tenía su sinónimo en Patria, Régimen e Iglesia. El skyline de la ciudad franquista ha roto los lazos para dar lugar a la Madrastra. En «Barojiana», el relato del servicio militar ordinario deja en claro esta inversión de la madre en palabras de un sargento: «A qué cuando veis un francés os da rabia? ¿Sí? Pues, "eso" es la Patria» [18].

Es por eso quizá que los espacios se definen por la ruptura de la guerra civil, cuyo exterior es amenazante, mientras que los espacios de lo interno, en esa lucha cuerpo a cuerpo, intentan transgredir para recuperar esa memoria invicta, aunque no siempre lo logren. Lo externo, en tan- 
to público, se rige por el carácter amenazante del Estado censor, mientras que lo interno, como espacio íntimo, permite muchas veces la liberación de los recuerdos. Espacios característicos son, sin lugar a duda, los ambientes de las tertulias, en especial, la de Baroja.

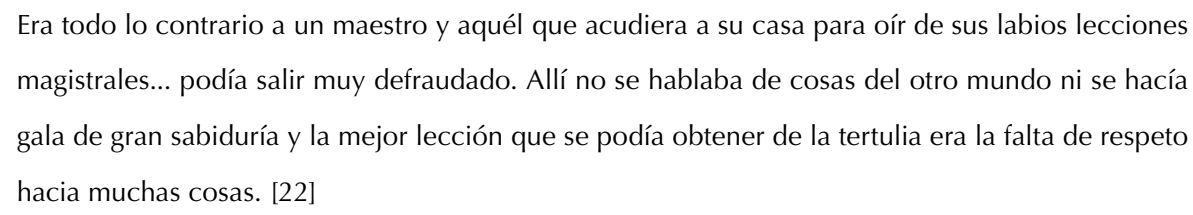

La casa del gallego Díaz, donde se impartían lecciones de matemática, nos muestra este cruce exacto entre lo externo y lo interno pero, ante todo, entre el pasado y el presente: el cristal del ventanal roto por una bomba caída en tiempos de la guerra, el frío consecuente en oposición a la calefacción de la Iglesia de los jerónimos, donde Gallego se refugiaba mientras jugaba el rol de confesor para luego comentar y volver risible aquello que había escuchado pero, ante todo, la mugre y el polvo del tiempo intemporalizado, estancado. La memoria, en su metáfora perfecta, funciona en estos textos tomando el cuerpo de la ciudad prodigio, Madrid. Los recuerdos de San Sebastián, en Martín Santos, mediando la cultura vasca, serán otro signo de identidad de la memoria republicana, junto con su relato decisivo de cambio ideológico. En este sentido, la ciudad madrileña es también, en ese gesto de resistencia, la ciudad intertextual, la ciudad leída en Tiempo de Silencio: la pensión de Luis, con la colcha roja de raso, doña Luisa y las famosas catoblepas, serán otro signo de la importancia de estos espacios clandestinos donde se intentaba tirar abajo el régimen. El ámbito de lo cafés, herencia liberal de los artículos de Larra, y otra vez el cruce intertextual, donde un escritor en el fondo, escibía sin parar, el Café del Lyon o el del Cock, donde se discutían las nuevas corrientes. Todo ese espacio a la luz cambia por el espacio clandestino; allí, los topoi se vuelven caractrísticos de la restricción y el racionamiento, en palabras de Martín Gaite. Pero esa memoria que se recolecta en los intersticios de esa ciudad que ha quedado, pese a todo, que se ha mantenido en pie, prevalece en lo público y lo invisible, y uno de sus referentes está en la figura del maitre, otro personaje histórico que sigue la tendencia barojiana:

Casi todos los maitres de Madrid habían militado en la CNT y (...), cuando ya cerrado el local, despachada la clientela y retirados los camareros, corría una última ronda y se evocaba la epopeya del puente de los franceses, el maitre-situado detrás de la barra como en sus años mozos- apenas 
podía retener las lágrimas. El tiempo es vuestro. Hay que aprovechar la juventud [101]

Esta recuperación del pasado pone en juego un último eje, el de la ciudad palimpsesto que es, ante todo, la puesta en escena de una memoria palimpsesto que es la de la ficción como matriz de conocimiento, un conocimiento no sólo del pasado sino del presente y de una reflexión programática acerca del futuro. He aquí el gesto ideológico, la aparición del intelectual crítico y la ficción como medio que no sólo aplica sino que ofrece un análisis esencial de una memoria discursiva: «Esa memoria es y será siempre un palimpsesto y cada nueva inscripción borra la anterior, y aun cuando la última no sea- y eso es más frecuente de lo que se confiesamás que una invención destinada a adaptar el pasado a las predilecciones del presente» [103]

A continuación analizaremos el ensayo, La construcción de la torre de Babel. Allí se despliegan las estrategias que, juntamente con las ya analizadas, nos permitirán abordar el corpus novelístico benetiano en el marco de los estudios sobre la memoria y la representación histórica.

\subsection{MEMORIA EN PALIMPSESTO: LA CONSTRUCCIÓN DE LA TORRE DE BABEL}

Podríamos definir palimpsesto como aquel ocultamiento que se establece en un texto al que se considera anterior, primigenio, cuyas huellas han sido borradas artificialmente. De alguna manera, se puede afirmar que todas las obras literarias traen a la memoria otras; por lo tanto, «todas las obras son hipertextuales» [Genette 1989: 19]), teniendo en cuenta que cada una lo será en mayor o menor grado. A esas relaciones «librescas» es a lo que Genette llama «literatura en segundo grado», es decir, literatura fundada en otros textos.

Por ello, el término palimpsestos acude a explicar, de manera general, cómo un texto se superpone al otro al que no oculta del todo sino que lo deja ver por transparencia [Genette 1989:495]. Al igual que la memoria, en tanto tejido, la obra literaria opera por capas o niveles de sentido. A la memoria le corresponden dos niveles que atraviesan la significación de los relatos que la ponen en escena: uno de referencia al pasado, que lo reformula o intenta imitar, como vimos en el relato testimonial y en el ensayo historiográfico; y otro anclado en el presente de la enunciación y que busca de esa referencia al pasado un sentido que sea de utilidad para el presente. Para explicar la hipertextualidad, Genette propone dos tipos de derivación hipertextual: transformación e imitación. Dichas categorías no encierran conceptos antagónicos, sino grados 
de relación intertextual. La transformación incluye la parodia, el travestimiento y la transposición. La imitación incluye el pastiche, el charge o imitación satírica y la forgerie o imitación seria. Un caso paradigmático que nos interesa tomar es el de la relación analógica respecto de La construcción de la torre de Babel. Nos referimos, por un lado, al conjunto de cinco breves ensayos, escritos entre 1984 y $1990^{31}$, y por el otro, al sentido figurado de la imagen que Benet analiza. La torre de Babel es, en principio, entendida como un mito que, como fondo de un tejido, entreteje historias. Como tal, permanece como una memoria en palimpsesto de la tradición latente no explicitada en el tejido evidente. Sobre este mito, Benet, no al azar, elige la versión de Brueghel. En ella, la obra no es un elemento estático sino, por el contrario, dinámico. No le interesa mostrar el sentido acabado de la obra sino la idea de construcción a partir de dos elementos: la dialéctica sujeto-objeto (por la que la obra no se determina a si misma sino a través de los ojos del sujeto que la recrea que, en este caso, es la figura humana en su totalidad) y la reformulación del sentido bíblico (que contradice la idea de unicidad por la de la multiplicidad y diversidad de la humanidad). Estos elementos se alejan de la figuración de la «cúspide para alcanzar a Dios», expresada en el Génesis, y proponen en la obra una puesta telescópica marcada por la superposición de elementos arquitectónicos en oposición a la estructura helicoidal. Es esta arquitectura lo que nos interesa por cuanto la idea de construcción —que es, en definitiva, lo que pintó Brueghel— está signada por niveles que atraviesan la temporalidad y hacen de la torre de Babel una imagen perfecta del funcionamiento de la memoria histórica. Cada nivel marca las prácticas de una memoria, que es también su hacer económico y social.

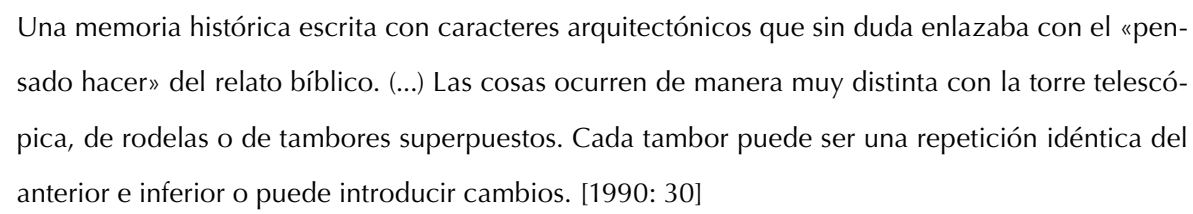

Por eso, el momento elegido es un estado de la memoria histórica. Allí nada está completo, todo permanece en la imperfección. Quizás esa imperfección sea lo que caracteriza el elemento principal de la memoria como una construcción plagada de reconstrucciones, reemplazos y reformulaciones. El tiempo que perdura, inevitablemente, es el presente.

31 Dichos ensayos fueron contribuciones orales a un curso universitario de verano sobre diversos asuntos, como el espía, la literatura medieval o la guerra civil. A los efectos del análisis, sólo tomaremos dos de estos ensayos. Excepto el primero, «La construcción de la torre de Babel», todos ya habían sido publicados en diversas revistas. 
Babel, como toda utopía, no es tanto una réplica al proyecto divino como una expropiación del mismo, no tanto una contrarreligión como una preterreligión que, incómoda con la idea de relegar la oferta divina a un futuro incierto y no testimoniado, se esfuerza en actualizar en un presente que, sin duda, pasará pronto a un bien cimentado e indestructible pasado. [38]

El rechazo de la idea de eternidad hace que la memoria sea un estado frágil que, de no ser testimoniada, especialmente en obras que logren superar al tiempo, tiende a perderse. Por eso la palabra es, para Benet, un mitema que se convierte en hilo conductor «de una experiencia que para redactar un discurso histórico tiene necesariamente que partir de una sintaxis analógica, pero nunca al revés». La memoria, que es lenguaje, está construida a la manera descripta por Brueghel, por tambores sucesivos que van reformulando los estadios anteriores, a la manera de un palimpsesto por el que, no obstante, pueden verse las prácticas de una generación anterior en constante proceso. Los estados de construcción serán centrales en las novelas, en especial, en torno de la memoria de la guerra civil. El ensayo titulado «Tres fechas. Sobre la estrategia en la Guerra Civil española», que retoma elementos temáticos y estilísticos de LCGC y QFGC, se centra en la construcción de la victoria nacionalista y la teoría que esboza será esencial en la estructuración de sus novelas, donde la memoria de la guerra atraviesa todos los niveles. La teoría señala que la guerra civil se centra en las ciudades. La conquista del Estado suponía la ocupación de las grandes ciudades pero, al fracasar en su mayor parte, con excepción de SeviIla y Zaragoza, la guerra debió extenderse. Es lo que veremos en el ciclo de HL. Los principios napoleónicos, mediante los cuales se había emprendido la guerra, la Niederwerfungsstrategie según los alemanes, que se basaba en el derrocamiento directo del enemigo, ya no tenía validez frente a la resistencia de las ciudades. Por eso se rescató la Ermattungsstrategie, es decir, la estrategia que proponía no la destrucción del ejército enemigo sino el agotamiento de sus recursos económicos. La metáfora de la caída del fruto maduro proporcionada por Franco señala que la caída de las grandes ciudades, en especial Madrid, sería producto de dicho agotamiento. Benet lo caracteriza en tres fechas sucesivas que van desde 1936 a 1938, fecha que determinará ya la finalización de la guerra: el 23 de noviembre de 1936, en el Terminus de Leganés, cuando Franco comprendió que no estaba preparado para una guerra ni tenía planes para afrontarla; el 25 de abril de 1937, cuando Franco le confesó al general Ungría que la guerra duraría dos años más. Ese tiempo le daba cierta ventaja, ya que mientras durase la guerra su jefatura de Estado 
recientemente estrenada no sería cuestionada así como tampoco tendría que preocuparse por la constitución del nuevo «Estado»; por último, el 1 de agosto de 1938, en el frente de Gandesa cuando, frente a la victoria, decidió optar por el camino más largo. Allí, Benet hipotetiza dos opciones:

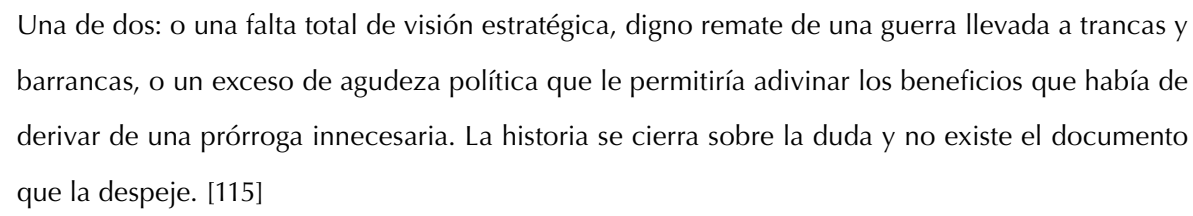

Esa inteligibilidad que analizamos en QFGC y LCGC hace que sea investigable. Incluso en la actualidad. La memoria de la guerra que persiste en palimpsesto se apoya en la memoria colectiva latente: es ese el problema que ocupa la narrativa benetiana. Como señala K. Benson, en Benet es clave el planteamiento antimimético, que produce una relación metafórica entre el mundo literario y la referencia histórica (tanto la experiencia traumática de la guerra como la de la etapa franquista). Por esto es tan importante la figura de la torre de Babel como proceso de construcción diacrónico que articula los diversos estados de la memoria histórica.

\section{CONCLUSIONES FINALES}

A lo largo de este trabajo hemos pretendido dar cuenta del estado de la cuestión de una filosofía de la historia después de Franco, puesto que, al hablar de una filosofía de la historia narrativista debemos partir necesariamente de una filosofía de la praxis que problematice la opacidad del lenguaje y la supuesta homogeneidad del sujeto. El discurso histórico es literatura por cuanto lleva la aplicación necesaria del pasado en el hic et nunc presente, y dicha aplicación está siempre bajo la mediación de la subjetividad. Ese rasgo supone un dispositivo moralizador que, en la recepción, obliga a la acción mediante la propuesta de un programa. Las esferas normativa, instrumental y estética que la modernidad había separado, en el discurso de la historia vuelven a conjugarse de manera problemática pero eficaz para comprender que los entramados textuales son reflejo, no de una realidad (en sentido mimético) del pasado sino, por el contrario, una construcción figurativa para el presente, cuyo sentido liter9al aún no se desvela y sólo se comprende por su connotación. En ese presente se incorpora también el problema de la memoria. 
cordarles. Es preciso recuperar sus vidas, sus esperanzas en el proyecto de una España republicana abortado por la sublevación militar de 1936. La asociación quiere instar a las administraciones, a la Universidad, a los colectivos cívicos a llevar a cabo una operación multidisciplinar para que nada se pierda: los testimonios, los documentos, la geografía de aquel genocidio: fosas, arquitectura carcelaria o relacionada con ella, etc. Todos estos elementos, debidamente conservados deben servir para componer lecciones de historia, de vida y de formación en ideales de solidaridad, pacifismo y tolerancia. [Amigos de los Caídos por la Libertad- Región Murcia 2002]

La memoria no sólo de la guerra sino también del período franquista que articula el marco teórico benetiano a partir de la intrahistoria viene a cortar con los grandes relatos falsificados de la historia oficial. Como hemos explicado, la memoria discursiva que se despliega se corresponde con los valores republicanos de democracia y reformismo, pero ambos no pueden aplicarse sin justicia. Hemos definido, siguiendo esa lógica, la memoria colectiva como una forma de justicia y sus relatos, así como los ensayos programáticos, devienen, por consiguiente, una conquista de la ética y de la moral. Por eso, dichas narrativas están plagadas de recursos moralizadores, como la ironía, el humor y la parodia. Quizás el proyecto literario benetiano, como los de muchos otros integrantes de la misma generación, intente rescatar esa memoria discursiva, política y social republicana desde una poética que no busca el realismo literal del período franquista sino, por el contrario, el realismo figurativo que sirva al presente como lugar de memoria activo, donde intervenga un narrador comprometido estética y políticamente con la memoria colectiva y la recuperación de la identidad invicta. Cabe citar, para culminar este panorama teórico-programático, a C. Martín Gaite, cuya escritura, al igual que la benetiana, se sostiene por el hilo de la memoria a la manera del hilo de Ariadna, que rompe con el mal del laberinto —o su mal de archivo- para construir la tentación moral del bien. Por eso, explica: «El hilo de todo lo que he escrito es la memoria, el deseo de encontrar cada cual su propia coherencia de memoria y olvido: entender cada uno el sitio donde está. Eso es muy difícil. La palabra bien dicha es memoria.» [Martín Gaite, C., 1999: 3] Memoria que en la actualidad aún sigue siendo un problema para la sociedad española, como lo demuestran las diversas columnas en diarios y revistas así como los debates parlamentarios y el descubrimiento de fosas comunes. Quizás la escritura, en un sentido positivo del pharmakon que Derrida le critica al platonismo en ese intento por deconstruir las oposiciones binarias, sirva para la cura de la memoria del mal porque la escritura no sería hipomnesis sino mneme; es decir, no una copia representativa y superficial de la memoria viva, 
sino la misma memoria in praesentia que ayuda a reconstruir el presente más que a actualizar el pasado construido, con sus tradiciones inventadas, del franquismo. Ese imaginario es el que se intenta superar con el acto de escritura.

Así, el acto narrativo de contar como forma de superación del pasado es también una catarsis; es decir, una superación, una purificación o cura del mal, de la enfermedad del olvido, porque es en sí una transformación.

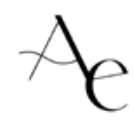

\section{Abreviaturas}

$\begin{array}{ll}\text { Londres victoriano } & \text { LV } \\ \text { Herrumbrosas lanzas } & \text { HL } \\ \text { La cultura en la guerra Civil } & \text { LCGC } \\ \text { Otoño en Madrid hacia } 1950 & \text { OM } \\ \text { Qué fue la guerra Civil } & \text { QFGC } \\ \text { Un viaje de invierno } & \text { UI } \\ \text { La sombra de la guerra } & \text { LSG } \\ \text { La inspiración y el estilo } & \text { IE } \\ \text { Sobre la incertidumbre } & \text { SI } \\ \text { La infidelidad del regreso } & \text { IR } \\ \text { Puerta de tierra } & \text { PT } \\ \text { En ciernes } & \text { EC }\end{array}$

\section{Bibliografía}

AA. VV (1986) La guerra Civil Española, 50 años después. Barcelona: Labor.

AA. VV., (1989) La Crisis del Estado: Dictadura, República, Guerra. (1923-1939), Colección dirigida por M. TUÑON de LARA. Barcelona: Labor.

AA.VV, (1993) Juan Benet: el caballero de Región. Madrid: Insula. N 559-560.

ALTHUSSER, L. (1970) Ideología y Aparatos ideológicos del Estado. México: FCE. 
ANKERSMIT, F. (2005) Historical experience.California: Stanford.

—_ (1994) Historia y Tropología. Ascenso y caída de la metáfora. Buenos Aires: FCE.

ARAQUISTÁN, L. (1990) El pensamiento español contemporáneo. Buenos Aires: Losada.

ASSMAN, J.(2008) Religión y memoria cultural. Córdoba: Lilmod.

_ (1992) Das kulturelle Gedächtnis: Schrift, Erinnerung und politische Identität in frühen Hochkulturen. München: C. H. Beck.

AUB, MAX (2002) La gallina ciega. Madrid: EDAF.

AUERBACH, E. (2004) Mimesis. México: FCE.

BACHELARD, G. (1998) La poética del espacio. México: FCE.

BAJTíN, M. (1997) Estética de la creación verbal. Buenos Aires: Siglo XXI.

BARTHES, R. (1996) Lo obvio y lo obtuso, Barcelona: Paidós.

__ (1977) Variaciones sobre la escritura. Buenos Aires: Paidós.

__ (1974) El grado cero de la escritura. Barcelona: Paidós.

__ (1967) El discurso de la historia, en El susurro del lenguaje. Buenos Aires: Paidós.

BELVEDRESI, E. (2006) «Consideraciones acerca de la utilidad de la Historia». Actas // Congreso Internacional de Filosofía de la Historia. Reescrituras de la Memoria social. Buenos Aires, octubre de 2006.

BENET, J. (1976) Qué fue la guerra civil. Madrid: La Gaya ciencia.

_ (1986) La cultura en la guerra civil. Madrid: La Gaya ciencia.

_ (1970) La inspiración y el estilo. Barcelona: Seix Barral.

_ (1970) Puerta de tierra. Barcelona: Seix Barral.

—_ (1976) El ángel del señor abandona a Tobías. Barcelona: La Gaya Ciencia.

_ (1981) La moviola de Eurípides. Madrid: Taurus.

__ (1987) Otoño en Madrid hacia 1950. Madrid: Visor. 
—_ (1990) La construcción de la Torre de Babel. Barcelona: Siruela.

_ (1989) Londres victoriano. Barcelona: Planeta.

— (1983) Herrumbrosas lanzas. Vol. 1. Madrid: Alfaguara.

— (1985) Herrumbrosas lanzas. Vol. 2. Madrid: Alfaguara.

— (1986) Herrumbrosas lanzas. Vol. 3. Madrid: Alfaguara.

BENSON, KEN (1989) Razón y espíritu: análisis de la dualidad subyacente en el discurso narrativo de Juan Benet. Stockholm: Stockholms Universitet.

BERGSON, H. (1968) Matière et mèmoire. Paris: P.U.F.

CARR, D. (1986) «Narrativa y el mundo real: un argumento para la continuidad». History and Theory, vol. XXV, n 2.

CAUDET, F. (2008). «¿De qué hablamos cuando hablamos de literatura de exilio republicano de 1939?». Memoria del I Congreso Internacional de Literatura y Cultura españolas contemporáneas. Siglos XX y XXI. La Plata: Unlp.

COLLINGWOOD, R. G. (2000) Idea de la Historia. México: FCE.

COLMEIRO, J. (2005) Memoria histórica e identidad cultural. De la Postguerra a la Postmodernidad. Madrid: Anthropos.

COURTINE, J. J. (1981) «Analyse du discours politique». Langages $N^{\circ} 62$.

CUESTA BUSTILLO, J. (1998) «Memoria e historia: un estado de la cuestión», en J. Cuesta Bustillo (ed.) Memoria e historia. Madrid: Marcial Pons.

DE LA GRANJA, JOSÉ LUISY ALBERTO REIG TAPIA (eds.) (1993). Manuel Tuñón de Lara: El compromiso con la Historia. Su vida y su obra. Bilbao: Universidad del País Vasco.

DERRIDA, J., (1989) La deconstrucción en las fronteras de la filosofía. Barcelona: Paidós.

DÍAZ PLAJA, FERNANDO (1994) La vida cotidiana en la España de la guerra civil. Madrid: Ediciones EDAF.

EAGLETON, T. (1997). Ideología. Buenos Aires: Paidós. 
FONTANA, JOSEP, (ed.) (1986). España bajo el franquismo. Barcelona: Critica.

FRIEDLÄNDER, S. (2008) En torno a los límites de la representación. Buenos Aires: UNQ.

FRYE, NORTHROP (1973) «Theory of Archetypal Meaning (2): Demonic Imagery». Anatomy of Criticism: Four Essays. Princeton, NJ: Princeton UP.

GARCÍA BERRIO, A. (1998) Teoría del discurso y Estética de la representación, Valencia: Consorci de Museus de la Generalitat.

GENNETTE, G (1989) Palimpsestos. Madrid: Taurus,

GINZBURG (1998) El queso y los gusanos. Madrid: Síntesis.

GOYTISOLO, J. (1999) «Memoria, olvido, amnesia y memoricidio». En: Cogitus interruptus. Barcelona: Seix Barral.

GRACIA GARCÍA, J.- CARNICER, J. (2000) La España de Franco (1939-1975). Madrid: Síntesis. GUARIGLIA, O. (1993) Ideología, Verdad y Legitimación. Buenos Aires: FCE.

GRASS, GÜNTER (1999) Artículos y ensayos, Barcelona: Círculo de Lectores.

HALBWACHS, M.(1997) Les Cadres Sociaux de la Mémoire. Paris: Albin Michel. (1968) La memoria colectiva. Paris: P.U.F.

HEGEL, F. (2004) Lecciones sobre la Filosofía de la Historia Universal. Madrid: Alianza.

HERZBERGER, DAVID (1976) The novelistic World of Juan Benet. Clear Creek: The American Hispanist.

HOBSBAWN, E. (1983) «Inventando tradiciones». El discurso histórico. Barcelona: Crítica.

HUTTON, P. (1993) History as an art of memory. Hanover, N.H: University Press of New England. ILIE, PAUL (1980). Literatura y exilio interior. Madrid: Fundamentos.

KELLNER, H. (1989) Language and History representation. Madison: The University of Wisconsin press.

KOSELLECK, R. (1979) Futuro pasado. Para una semántica de los tiempos históricos. Barcelona: 
Paidós.

KRISTEVA, J. (1988) Poderes de la Perversión. Buenos Aires: Siglo XXI.

LABANYI, J. (2000) «History and Hauntology; or What does one do with the ghosts of the past? Reflections on spanish film and fiction of the Post Franco period» En: Resina, J. R. (Ed.) Disremembering the Dictatorship: the politics of memory in the Spanish transition to Democracy. Amsterdam: Rodopi.

LAKOFF, G., Y JOHNSON, M. (1995) Metáforas de la vida cotidiana. Madrid: Cátedra.

— Y TURNER, M. (1989) More than cool reason. London: The University of Chicago Press. Trad. de L. Eisner.

LEVI, P. (1986) Si esto es un hombre. Barcelona: Muchnik.

LONGHURST, C. (1974) «Historia y Ficción: concepto barojiano de la novela histórica». En: Las novelas históricas de Pio Baroja. Madrid: Guadarrama.

LOTMAN, I. (1979) La semiósfera. Madrid: Cátedra.

MARGALIT, A. (2002) Ética del recuerdo. Lecciones Max Horkheimer. Barcelona: Herder.

MARTÍN GAITE, CARMEN (1999) «Dos textos inéditos» [epílogo a la edición de La inspiración y el estilo. Madrid: Alfaguara. Págs. 225-269.

NORA, P. (1997) Les lieux de mémoire. Paris: Gallimard.

__ (1984) «Entre Mèmoire et Histoire. La problèmatique de lieux». En: Lieux mèmoire. Paris: Gallimard.

PRESTON, PAUL (ed) (1978). España en crisis. Evolución y decadencia del régimen de Franco. México: FCE.

REIG TAPIA, ALBERTO (1999) Memoria de la Guerra Civil. Los mitos de la tribu. Madrid: Alianza. RICOEUR, P. (2000) La memoria, la historia, el olvido. México: FCE.

__ (1985) Tiempo y Narración. Madrid: Cristiandad.

_ (1999) La lectura del tiempo pasado: memoria y olvido. Madrid: Arrecife. 
ROBIN, R. (1980) Los manuales de Historia de la III República francesa: un problema de hegemonía ideológica. En: Monteforte Toledo M., (1980) El discurso político. México: Nueva imagen. — (1996) Identidad, memoria y relato. La imposible narración de sí mismo. Buenos Aires: Of. de Publicaciones del CBC.

RUNIA, E. (2006) Burying the dead, creating the past. Ponencia presentada en el II Congreso Internacional de Filosofía de la Historia. Reescrituras de la Memoria social. Buenos Aires, octubre de 2006.

SEMPRÚN, J. (1998) La escritura o la vida. Madrid: Cátedra.

SILVA, EMILIO (2002). «Las tareas pendientes». El País. 15 de diciembre.

SOLDEVILA DURANTE, I. (2001) Historia de la novela española (1936-2000) V. I. Madrid: Cátedra.

TRAVERSO, E. (2000) El pasado, instrucciones de uso. Historia, memoria, política. Madrid: Marcial Pons.

TODOROV, T. (2000) Los abusos de la memoria. Barcelona: Paidós.

TODOROV, T. (2000b) Memoria del mal, tentación del bien. Indagación sobre el siglo XX. Barcelona: Península.

TUSELL, JAVIER (2002). «Alfonso XIII, un centenario polémico». El País. 5 de junio.

VALDÉS, MARIO J. (1989) «Teoría de la hermenéutica fenomenológica», en Graciela Reyes, ed. Teorías literarias en la actualidad. Madrid: El arquero.

VERNON, KATHLEEN M. (1989) «El lenguaje de la memoria en la narrativa española contemporánea», en Neumeister-Sebastián (ed.); Heckelmann-Dieter (introd.); Mergalli-Franco (introd.), Actas del IX Congreso de la Asociación Internacional de Hispanistas, I \& II, Frankfurt: Vervuert. VÁZQUEZ MONTALBÁN (1998) La literatura en la construcción de la ciudad democrática. Madrid: Crítica.

— (1986). Crónica sentimental de España. Barcelona: Destino.

VERNANT, J. P. (1998) «Historia de la memoria y memoria histórica», en: ¿Por qué recordar? 
Madrid: Granica.

VICO, G. (1995) Ciencia nueva. Madrid: Tecnos.

VIRNO, PAULO (2003) El recuerdo del presente. Ensayo sobre el tiempo histórico. Buenos Aires: Paidós.

WEINRICH, H. (1978) Estructura y función de los tiempos en el lenguaje. Madrid: Gredos.

WHITE, H. (1987) El contenido de la forma. Narrativa, discurso y representación histórica. U.P: J. Hopkins.

(1978) «Teoría literaria y escrito histórico». En White (2003), H. El texto histórico como artefacto literario. Buenos Aires: Paidós.

WINTER, U. (Ed.) (2006) Lugares de la memoria de la Guerra civil y el Franquismo. Representaciones literarias y visuales. Madrid: Iberoamericana.

ZIZEK, S. (2003). Ideología: un mapa de la cuestión. Buenos Aires: FCE. 